Article

\title{
Antioxidant and Antimicrobial Activities of 7-Hydroxy- calamenene-Rich Essential Oils from Croton cajucara Benth.
}

\author{
Mariana M. B. Azevedo ${ }^{1, *}$, Francisco C. M. Chaves ${ }^{2}$, Catia A. Almeida ${ }^{3}$, Humberto R. Bizzo ${ }^{4}$, \\ Rafael S. Duarte ${ }^{3}$, Galba M. Campos-Takaki ${ }^{5}$, Celuta S. Alviano ${ }^{3}$ and Daniela S. Alviano ${ }^{3}$ \\ 1 Chemistry Institute, Federal University of Rio de Janeiro (UFRJ), CT, Ilha do Fundão, \\ Rio de Janeiro 21941-909, RJ, Brazil \\ 2 EMBRAPA Western Amazon, Rodovia AM 10, km 29, Manaus 69010-970, AM, Brazil \\ 3 Institute of Microbiology Paulo de Góes, Federal University of Rio de Janeiro (IMPG-UFRJ), \\ CCS, Ilha do Fundão, Rio de Janeiro, RJ 21941-590, Brazil \\ 4 EMBRAPA Food Agroindustry, Avenida das Américas 29501, Rio de Janeiro 23020-470, RJ, Brazil \\ 5 Center for Research in Environmental Sciences, Catholic University of Pernambuco, \\ Rua do Príncipe 526, Recife 50050-900, PE, Brazil \\ * Author to whom correspondence should be addressed; E-Mail: marimbarros@gmail.com; \\ Tel.: +55-21-2562-6711.
}

Received: 29 November 2012; in revised form: 4 January 2013 / Accepted: 11 January 2013 / Published: 16 January 2013

\begin{abstract}
Croton cajucara is a shrub native to the Amazon region locally known as "sacaca". Two morphotypes are known: white and red "sacaca". The essential oils (EO) obtained by hydrodistillation from leaves of the red morphotype were, in general, rich in 7-hydroxycalamenene $(28.4 \%-37.5 \%)$. The effectiveness of these EO regarding the antimicrobial activity against pathogenic microorganisms was initially investigated by the drop test method, showing significant inhibition zones. Among the microorganisms tested, the essential oils rich in 7-hydroxycalamenene were more effective against methicillin resistant Staphylococcus aureus (MRSA), Enterococcus faecalis, Mycobacterium tuberculosis, M. smegmatis, Mucor circinelloides and Rhizopus oryzae. The minimum inhibitory concentrations (MIC) of the oils were determined using the broth dilution assay. It was possible to observe that 7-hydroxycalamenene-rich oils presented high antimicrobial activity, with MIC of $4.76 \times 10^{-3} \mu \mathrm{g} / \mathrm{mL}$ for MRSA, $4.88 \mu \mathrm{g} / \mathrm{mL}$ for $M$. tuberculosis, $39.06 \mu \mathrm{g} / \mathrm{mL}$ for M. smegmatis, and $0.152 \mu \mathrm{g} / \mathrm{mL}$ for $R$. oryzae and $3.63 \times 10^{-8} \mu \mathrm{g} / \mathrm{mL}$ for M. circinelloides. The antioxidant activity of this EO suggests that 7-hydroxycalamenene provides more antioxidant activity according with $\mathrm{EC}_{50}$ less than $63.59 \mu \mathrm{g} / \mathrm{mL}$.
\end{abstract}


Considering the bioactive potential of EOs and 7-hydroxycalamenene could be of great interest for development of antimicrobials for therapeutic use in treatment of bacterial and fungal infections in humans and/or veterinary practice.

Keywords: Croton cajucara; 7-hydroxycalamenene; essential oils; antimicrobial activity; antioxidant activity

\section{Introduction}

Croton cajucara Benth. (Euphorbiaceae) has been a very important traditional medicinal plant in Brazil. It occurs widely in the Brazilian Amazon rainforest region where it is popularly known as "sacaca". Infusions of the stem bark have been used for the treatment of liver and kidney disorders, diabetes, diarrhea, stomach ache, fever, jaundice, hepatitis, malaria and also to lower blood cholesterol. Although the use of leaves for losing weight has been encouraged in the Brazilian Amazon region, toxic hepatitis frequently appears as a side effect. This observation may be correlated to the chronic use required for losing weight, since a lack of acute hepatotoxicity has been described and this toxicological effect was not noticed [1,2].

Two morphotypes of C. cajucara are known: white "sacaca" and red "sacaca", mainly identified by young leaf colour and steams [3]. In general, essential oils from the white morphotype are rich in linalool, while those from red morphotype are rich in 7-hydroxycalamenene, although some exceptions have been observed and, therefore, this substance cannot be used as a chemical marker $[3,4]$. The linalool-rich essential oil from the leaves of $C$. cajucara has been shown to be very toxic for Leishmania amazonensis and Candida albicans [5,6].

The objective of this work was to evaluate the antimicrobial and antioxidant activities of the essential oils from the leaves of Croton cajucara with different contents of 7-hydroxycalamenene.

\section{Results and Discussion}

The average oil yield obtained was $0.65 \%$ (dried basis). The major compounds present in the essential oils from C. cajucara used are shown in Table 1. Quantitative and/or qualitative variations were observed among samples of red "sacaca". For one individual, no 7-hydroxycalamenene was detected and $\alpha$-pinene was the major component of the oil, as shown in Table 1.

The results for antimicrobial activity of the C. cajucara essential oils are presented in Table 2. For filamentous fungi the largest inhibition zone was obtained with 7-hydroxycalamenene-rich essential oils. For M. smegmatis, the best results were with SV002 (without 7-hydroxycalamenene and with $\alpha$-pinene), and SV004 and SV005 (over 30\% of 7-hydroxycalamenene). Although, the lowest inhibition zone was obtained through SV001 (containing 7-hydroxycalamenene and $\alpha$-pinene). For E. faecalis, S. epidermidis, MRSA and $L$. casei the largest inhibition zones were all associated with a high content of 7-hydroxycalamenene, which may indicate that this substance might be responsible for the inhibitory activity. The difference of inhibition zones can be justified by differences of boiling point (bp) values of compounds (e.g., bp of $\alpha$-pinene $52.5^{\circ}$ ). It is important to observe those values 
because the compounds present in the essential oil can change the atmosphere and interfere on microbial growth. Tullio et al. (2006) [7] showed that Mucor spp. and Rhizopus spp. exhibited susceptibility to pine essential oil ( $55.7 \%$ of $\alpha$-pinene) vapor.

Table 1. Main components from C. cajucara essential oils.

\begin{tabular}{cccccc}
\hline \multirow{2}{*}{ Components } & \multicolumn{5}{c}{ Samples (in\%) } \\
\cline { 2 - 6 } & SV001 & SV002 & SV003 & SV004 & SV005 \\
\hline$\alpha$-Pinene & 7.5 & 24.7 & 0.1 & 0.5 & $\mathrm{t}$ \\
Linalool & 6.3 & 11.6 & 11.0 & 9.9 & 13.2 \\
7-Hydroxycalamenene & 37.5 & n.d. & 28.4 & 30.9 & 32.9 \\
$\beta$-Caryophyllene & 4.1 & 5.7 & 2.8 & 4.0 & 2.6 \\
\hline
\end{tabular}

n.d.: not detected; t: trace (less than $0.1 \%$ ).

Table 2. Inhibition zones (in $\mathrm{mm}$ ) for C. cajucara essential oils.

\begin{tabular}{cccccc}
\hline Microorganisms & SV001 & SV002 & SV003 & SV004 & SV005 \\
\hline A. fumigatus & 4.8 & 3.2 & 4.5 & 4.6 & 5 \\
A. niger & 5.7 & 3.4 & 5.6 & 5.9 & 6 \\
A. ochraceus & 4.5 & 3.1 & 4.5 & 4.7 & 5 \\
F. solani & 3.1 & 2.2 & 3.4 & 3.5 & 3.5 \\
M. gypseum & 14 & 3 & 13 & 14 & 14 \\
M. circinelloides & 8 & 15 & 6 & 10 & 10 \\
R. oryzae & 6 & 12 & 5 & 8 & 10 \\
T. rubrum & 5.8 & 0 & 5.5 & 5.7 & 6 \\
M. smegmatis & 10 & 24 & 12 & 18 & 18 \\
E. faecalis & 10 & 6 & 8 & 6 & 9 \\
S. epidermidis & 6 & 9 & 7 & 8 & 20 \\
S. aureus MRSA & 7 & 5 & 7 & 13 & 38 \\
L. casei & 8 & 7 & 35 & 11 & 14 \\
C. albicans & 6 & 10 & 7 & 8 & 8 \\
\hline
\end{tabular}

For TLC and, therefore, bioautography, linalool and 7-hydroxycalamenene presented quite close $\mathrm{R}_{\mathrm{f}}$ values ( 0.43 and 0.58 , respectively), so the oil SV002 was chosen for bioautography to evaluate only the effect of linalool on the microorganisms tested. For this sample (with $11.6 \%$ of linalool) inhibition was observed for C. albicans but not for MRSA. While for SV001 showed strong inhibition in both microorganisms.

In Table 3 the MIC values for M. smegmatis, M. tuberculosis, S. aureus MRSA, C. albicans, $M$. circinelloides and $R$. oryzae can be observed. The microorganisms tested were susceptible at different concentrations to the oils rich in 7-hydroxycalamenene. This result may be due to differences in composition and, consequently, the interaction of the essential oil with the culture medium. The activity of 7-hydroxycalamenene-rich essential oil is confirmed by the values of MIC of 7-hydroxycalamenene isolated. 
Table 3. MICs values (in $\mu \mathrm{g} / \mathrm{mL}$ ) of essential oil samples.

\begin{tabular}{ccccccc}
\hline Microorganisms & SV001 & SV002 & SV003 & SV004 & SV005 & 7-OH \\
\hline M. smegmatis & 39.06 & 5000 & 78.12 & 156.25 & 156.25 & 39.06 \\
M. tuberculosis & 4.88 & 4.88 & 4.88 & 4.88 & 4.88 & 312.5 \\
MRSA & 0.019 & na & 0.019 & 0.004 & 0.001 & 39.06 \\
C. albicans & 1.22 & 1250 & 156.25 & 0.001 & 0.038 & 78.125 \\
M. circinelloides & nd & nd & nd & nd & $3.63 \times 10^{-8}$ & 19.53 \\
R. oryzae & nd & nd & nd & nd & 0.152 & 39.06 \\
\hline
\end{tabular}

na: no activity; nd: not determined; 7-OH: 7-hydroxycalamenene.

According to Sun et al. (2002) [8] the $\mathrm{MICs}_{80}$ of posaconazole, amphotericin B and itraconazole were $0.125,0.25$ and $0.25 \mu \mathrm{g} / \mathrm{mL}$ for Mucor ramosissimus and $8,0.25$ and $8 \mu \mathrm{g} / \mathrm{mL}$ for Mucor circinelloides, respectively. Comparing the above with the MICs obtained with the essential oils of five samples of red "sacaca", the latter showed more effectivity. The MICs of amphotericin B, itraconazole and posaconazole for $R$. oryzae were $1,0.5$ and $0.25 \mu \mathrm{g} / \mathrm{mL}$, respectively [9]. These results when compared to the MIC obtained with sample 5 from red "sacaca" show that this is more effective than amphotericin $\mathrm{B}$, itraconazole and posaconazole.

C. albicans was susceptible to the oils tested, achieving very close results when compared to a MIC of $1.6 \mu \mathrm{g} / \mathrm{mL}$ for amphotericin B. For MRSA the 7-hydroxycalamenene-rich oils were far more active than reference drugs, with MICs ranging from 1.19 to $19.07 \mathrm{ng} / \mathrm{mL}$, against $250 \mathrm{ng} / \mathrm{mL}$ for ciprofloxacin [10].

The MICs for M. tuberculosis and M. smegmatis have shown promising values when compared with Stephan et al. (2004) [11], whose MICs of various antibiotics for M. smegmatis were less effective than the red "sacaca" essential oils. According to data provided by the authors the essential oils are more effective or as effective as isoniazid, cycloserine, erythromycin and the cephalosporins. Only sample SV002 (without 7-hydroxycalamenene) had weak activity against M. smegmatis. According Wiid et al. (1999) [12], Maus et al. (2005) [13] and Shandil et al. (2007) [14] the major antimicrobial MICs for $M$. tuberculosis are $0.5 \mu \mathrm{g} / \mathrm{mL}$ for moxifloxacin, $0.5 \mu \mathrm{g} / \mathrm{mL}$ for ofloxacin, $0.1 \mu \mathrm{g} / \mathrm{mL}$ for sparfloxacin, $0.1 \mu \mathrm{g} / \mathrm{mL}$ for ciprofloxacin, $10 \mu \mathrm{g} / \mathrm{mL}$ for capreomycin, $10 \mu \mathrm{g} / \mathrm{mL}$ for viomycin, $5 \mu \mathrm{g} / \mathrm{mL}$ for kanamycin, $4 \mu \mathrm{g} / \mathrm{mL}$ for amikacin and $0.05 \mu \mathrm{g} / \mathrm{mL}$ to isoniazid. Despite the MICs of some antimicrobial drugs being more effective, the results showed the activity of essential oils was as effective or more effective than amikacin, kanamycin, capreomycin and viomycin. With these results, they can be considered effective since substances with antagonistic activity may exist in the essential oils.

The microbicidal activity of 7-hydroxycalamenene at MIC values was observed for all microorganisms tested. Although the essential oil results are very promising, 7-hydroxycalamenene shows quite increased MIC values. Although the high activity of essential oil could be justified, as due to sensitivity of the differences between the MICs of essential oils and 7-hydroxycalamenene, our results demonstrate that 7-hydroxycalamenene is active on a broad spectrum of microorganisms.

It is usually considered that strong activity corresponds to MIC values between 0.05 and $0.50 \mathrm{mg} / \mathrm{mL}$, moderate activity values between 0.6 and $1.50 \mathrm{mg} / \mathrm{mL}$ and above $1.50 \mathrm{mg} / \mathrm{mL}$ as weak activity [15]. According to this classification it could be stated that oils from the red morphotypes with 
high content of 7-hydroxycalamenene and 7-hydroxycalamenene isolated present high activity against the most of microorganisms tested.

The antioxidant activity was evaluated after TLC of the oil. It was possible to identify regions containing substances with activity even after $45 \mathrm{~min}$ of application of DPPH. The antioxidant activity was associated to 7-hydroxycalamenene (center spot) and $\beta$-caryophyllene (upper spot).

A quantitative evaluation was performed (Figure 1), and the logarithmic and linear regressions were obtained for the calculation of $\mathrm{EC}_{50}$. These values were: SV001-45.23 $\mu \mathrm{g} / \mathrm{mL}, \mathrm{SV} 003-63.59 \mu \mathrm{g} / \mathrm{mL}$, SV004-54.06 $\mu \mathrm{g} / \mathrm{mL}, \mathrm{SV} 005-44.4 \mu \mathrm{g} / \mathrm{mL}$ and 7-hydroxycalamenene-35.64 $\mu \mathrm{g} / \mathrm{mL}$. The $\mathrm{EC}_{50}$ of ascorbic acid, quercetin and rutin were, respectively, $2.84 \mu \mathrm{g} / \mathrm{mL}, 6.12 \mu \mathrm{g} / \mathrm{mL}$ and $9.3 \mu \mathrm{g} / \mathrm{mL}$.

Figure 1. Comparison between presence of 7-hydroxycalamenene $(\square)$ and $\mathrm{EC}_{50}(\square)$ of standards, essential oils and 7-hydroxycalamenene.

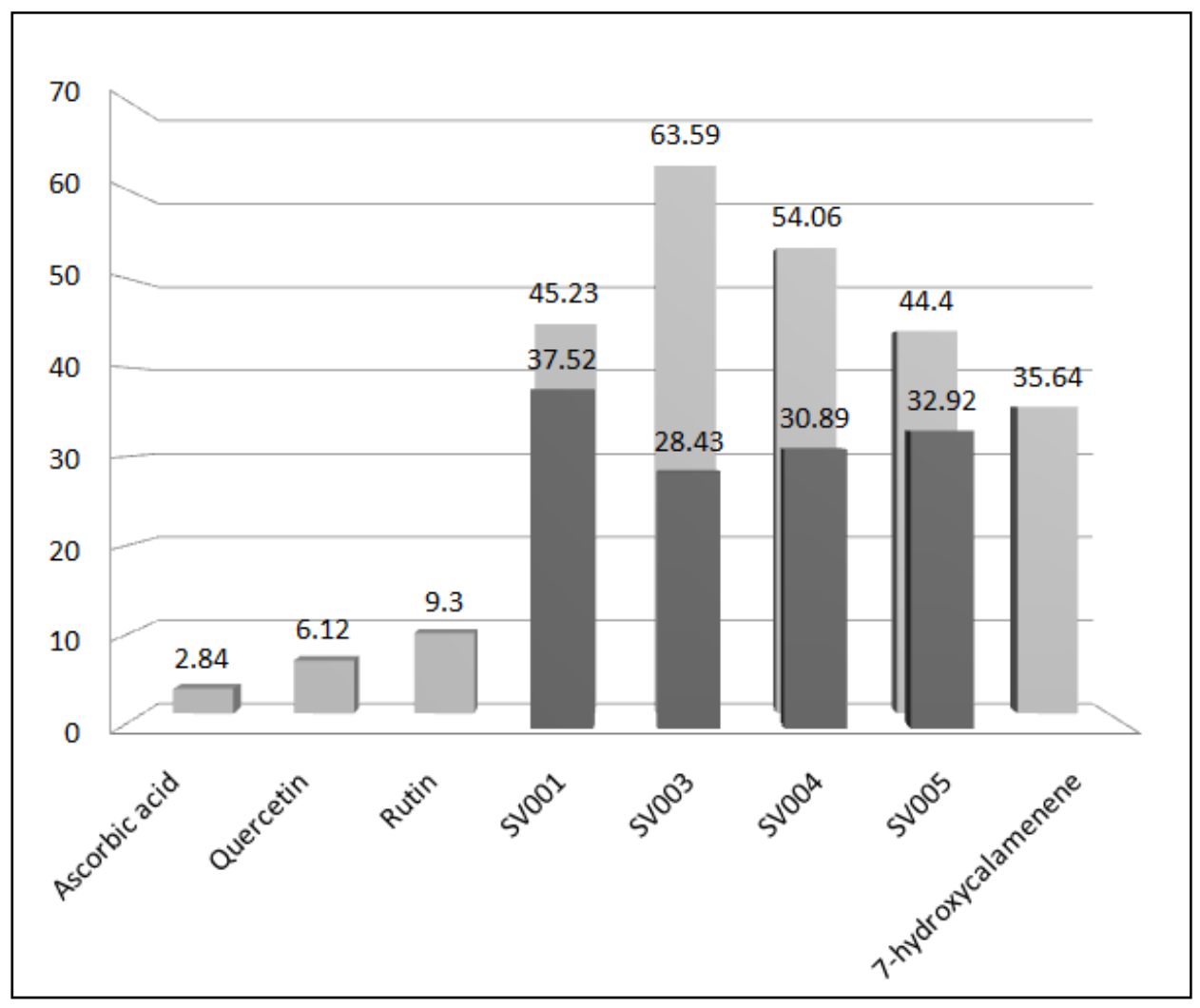

According to these results, we can suggest that in all samples with 7-hydroxycalamenene tested present promising antioxidant activity.

\section{Experimental}

\subsection{Plant Material}

Five individuals of red morphotype of $C$. cajucara were kept in the germplasm bank under the same cultivation practices. The leaves were collected between $8 \mathrm{~h}$ and $9 \mathrm{~h}$. A voucher specimen was deposited at EMBRAPA Amazônia Ocidental Herbarium (registry IAN 165013). 


\subsection{Chemicals}

All solvents used were spectroscopic grade from Tedia (Fairfield, OH, USA). Reagents were from Sigma-Aldrich (St. Louis, MO, USA). Column and planar chromatographic products were obtained from Merck (Darmstadt, Germany).

\subsection{Extraction and Analysis of the Essential Oils}

Extraction was performed by hydrodistillation in a modified Clevenger apparatus for $4 \mathrm{~h}$, according Pereira et al. (2011) [4]. The oils were analyzed on an Agilent (Palo Alto, CA, USA) 6890N gas chromatograph fitted with a 5\% phenyl $-95 \%$ methylsilicone (HP-5, $30 \mathrm{~m} \times 0.32 \mathrm{~mm} \times 0.25 \mu \mathrm{m}$ ) fused silica capillary column. The oven temperature was programmed from $60{ }^{\circ} \mathrm{C}$ to $240{ }^{\circ} \mathrm{C}$ $\left(3{ }^{\circ} \mathrm{C} / \mathrm{min}\right.$ ), and hydrogen was used as carrier gas $(1.4 \mathrm{~mL} / \mathrm{min})$. It was injected $1.0 \mu \mathrm{L}$ of a $1 \%$ solution of the oil in dichloromethane, in split mode $(1: 100)$. Injector was kept at $250{ }^{\circ} \mathrm{C}$ and detector (FID) at $280^{\circ} \mathrm{C}$. All analyses were performed in triplicate.

Mass spectra were obtained in an Agilent 5973N system operating in electronic ionization mode (EI) at $70 \mathrm{eV}$, with scan mass range of 40-500 m/z. Sampling rate was $3.15 \mathrm{scan} / \mathrm{s}$. Ion source was kept at $230{ }^{\circ} \mathrm{C}$, mass analyzer at $150{ }^{\circ} \mathrm{C}$ and transfer line at $260{ }^{\circ} \mathrm{C}$. The mass detector was coupled to an Agilent 6890 gas chromatograph fitted with a low bleeding 5\% phenyl-95\% methylsilicone (HP-5 MS, $30 \mathrm{~m} \times 0.25 \mathrm{~mm} \times 0.25 \mu \mathrm{m}$ ) fused silica capillary column. Injection procedure and oven temperature program were the same as above. Helium was the carrier gas, at $1.0 \mathrm{~mL} / \mathrm{min}$.

Linear retention indices (LRI) were measured by injection of a series of $n$-alkanes $\left(\mathrm{C}_{7}-\mathrm{C}_{26}\right)$ in the same column and conditions as above for GC analyses [16]. Identification of the oil components was based on computer search using the Wiley 6th ed. Library of Mass Spectral Data and by comparison of their calculated LRI with literature data [17]. 7-Hydroxycalamenene was isolated according to Azevedo et al. (2012) [10]. Linalool was also identified by injection of an authentic standard.

\subsection{Microorganisms}

The strains used to examine the antimicrobial activity of essential oils were methicillin-resistant Staphylococcus aureus (MRSA-BMB9393); Enterococcus faecalis, Staphylococcus epidermidis and Lactobacillus casei (Hospital Clementino Fraga Filho, UFRJ-HUCFF/UFRJ); Mycobacterium smegmatis (00061) and Mycobacterium tuberculosis H37Rv (ATCC 27294); Candida albicans (ATCC 24433); Aspergillus fumigatus (ATCC 16913), Aspergillus niger (HUCFF/UFRJ), Aspergillus ochraceus (ATCC 22947), Mucor circinelloides (LIKA0066), Rhizopus oryzae (UCP1506), Trichophyton rubrum (T544), Fusarium solani, Microsporum gypseum (HUCFF/UFRJ). The microorganisms were stored in specific culture media slanted tubes at $4{ }^{\circ} \mathrm{C}$. Prior to use, the microorganisms were grown in BHI agar for $24 \mathrm{~h}$ (for bacteria and yeast), in Potato Dextrose agar (PDA) for 5 days (for filamentous fungi); in Mueller-Hinton agar for 7 days (for M. smegmatis) and in Middlebrook 7H10 agar for 28 days (for M. tuberculosis). 


\subsection{Antimicrobial Analysis of the Essential Oils}

The antimicrobial assay was carried out by the drop agar diffusion method. The microorganisms were spread over Petri plates containing BHI agar, for bacteria and Candida, 7H10, for mycobacterium, and PDA for filamentous fungi. After $10 \mathrm{~min}, 10 \mu \mathrm{L}$ of the essential oils was added to the center of each plate. All plates were incubated according to the microorganisms, after which the diameter of inhibition zone (in $\mathrm{mm}$ ) was measured [18].

\subsection{Thin-layer Chromatography (TLC) and Bioautography}

All the oils were applied on Merck (Darmstadt) silica-gel G60 $\mathrm{F}_{254}$ chromatoplates and eluted with hexane-ethyl acetate (9:1). Spots were observed under UV light (254 nm), then stained with sulphuric anisaldehyde and heating. For the bioautography the TLC was repeated, but after elution and solvent drying the plates were exposed to UV for $20 \mathrm{~min}$, then added to sterile Petri plates and immediately covered with $6 \mathrm{~mL}$ of BHI previously inoculated with the microorganisms to be tested (circa $10^{6}$ to $10^{8}$ cells $\left./ \mathrm{mL}\right)$. After incubation period, the plates were observed and the inhibition zones were marked with 3-(4,5-dimethyl-2-thiazolyl)-2,5-diphenyl-2H-tetrazolyum bromide (MTT) [19].

\subsection{Minimal Inhibitory Concentration (MIC) and Minimum Microbicidal/Microbiostatic}

\section{Concentration Assays}

The in vitro susceptibility was determined by the minimum inhibitory concentration determination method. The MICs of 7-hydroxycalamenene-rich essential oils were determined by two-fold serial dilution as described by the Clinical and Laboratory Standards Institute (M27-A2, M38-A, M24-A, M7-A6) [20-23].

In the first well $0.5 \mu \mathrm{L}$ of essential oil was applied individually to initiate the serial microdilution and microbial suspension equivalent to 0.5 McFarland standard. To confirm the results $30 \mu \mathrm{L}$ of $0.005 \%$ resazurin in PBS ( $\mathrm{pH} 7.2$ ) were used. The negative and positive controls comprised pure growth media and inoculated growth media without test agent, respectively. The experiments were performed in triplicate and at least three times.

The microbicidal/microbiostatic concentrations were determined by sub-culturing the test dilutions onto a specific fresh solid media and incubating further for $18-72 \mathrm{~h}$, for bacteria and fungi, and 7-28 days for mycobacteria. The highest dilution that yielded no bacterial/fungal growth on solid medium was taken as microbicidal/microbiostatic concentrations [24].

\subsection{Antioxidant Activity}

The antioxidant activity was evaluated qualitatively [25] by application of $0.5 \mu \mathrm{L}$ of each essential oil and 7-hydroxycalamenene on a plate of silica-gel $60 \mathrm{~F}_{254}$ and eluting as described above. The plates were treated with a $0.2 \%$ methanolic solution of DPPH and the read just after spraying and after $45 \mathrm{~min}$. For quantitative evaluation, serial dilutions in ethanol of each essential oil were performed [26]. Reading of antioxidant activity was obtained after addition of $60 \mu \mathrm{L}$ of ethanolic solution of $0.3 \mathrm{mM}$ DPPH and under $492 \mathrm{~nm}$ wavelength after $30 \mathrm{~min}$. Ascorbic acid, rutin and quercetin were used as 
reference standards. The result was converted to percentage antioxidant activity using the following formula:

$$
\mathrm{AA} \%=100-\left\{\left[\left(\mathrm{Abs}_{\text {sample }}-\mathrm{Abs}_{\text {Blank }}\right) \times 100\right] /\left(\mathrm{Abs}_{\text {Control }}-\mathrm{Abs}_{\text {Blank }}\right)\right\}
$$

The $\mathrm{EC}_{50}$ values, half of the antioxidant activity, were calculated from logarithmic or linear regression, where the abscissa represents the concentration of essential oil tested and ordered the average percentage of antioxidant activity from five separate tests.

\section{Conclusions}

Samples of C. cajucara essential oils presented differences in the chemical composition, although all samples are rich in 7-hydroxycalamenene (except SV002). The oils containing high amounts of this compound were effective against methicillin-resistant $S$. aureus, M. smegmatis, M. tuberculosis, $M$. circinelloides and $R$. oryzae. In addition, it presented as a potent antioxidant.

The assessment of antibacterial, antimycobacterial and antifungal activities showed that the most active compound was 7-hydroxycalamenene. Nevertheless, it's necessary to confirm its viability in the formulation of new drugs by toxicity assays of 7-hydroxycalamenene as well as complementary studies aiming to investigate the possible mechanisms of action and the activity of this substance for other clinically important microorganisms.

\section{Acknowledgements}

This work was supported by Coordenação de Aperfeiçoamento de Pessoal de Nível Superior (CAPES), Conselho Nacional de Desenvolvimento Científico e Tecnológico (CNPq) and Fundação de Amparo a Pesquisa do Estado do Rio de Janeiro (FAPERJ).

\section{References}

1. Hiruma-Lima, C.A.; Gracioso, J.S.; Bighetti, E.J.B.; Grassi-Kassisse, D.M.; Nunes, D.S.; Souza Brito, A.R.M. Effect of essential oil obtained from Croton cajucara Benth. on gastric ulcer healing and protective factors of the gastric mucosa. Phytomedicine 2002, 9, 523-529.

2. Perazzo, F.F.; Carvalho, J.C.T.; Rodrigues, M.; Morais, E.K.L.; Maciel, M.A.M. Comparative anti-inflammatory and antinociceptive effects of terpenoids and an aqueous extract obtained from Croton cajucara Benth. Rev. Bras. Farmacogn. 2007, 17, 521-528.

3. Chaves, F.C.M.; Bizzo, H.R.; Angelo, P.M.C.; Xavier, J.J.B.N.; Sá-Sobrinho, A.F. Rendimento e Composição Química do Óleo Essencial de Folha de Dois Morfotipos de Sacaca (Croton cajucara Benth.). Rev. Bras. Pl. Med. 2006, 8, 117-119.

4. Pereira, A.Q.; Chaves, F.C.M.; Pinto, S.C.; Leitão, S.G.; Bizzo, H.R. Isolation and Identification of cis-7-Hydroxycalamenene from the Essential Oil of Croton cajucara Benth. J. Essent. Oil Res. 2011, 23, 20-23.

5. Rosa, M.S.C.S.; Mendonça-Filho, R.R.; Bizzo, H.R.; Rodrigues, I.A.; Soares, R.M.A.; Souto-Padrón, T.; Alviano, C.S.; Lopes, A.H.C.S. Antileishmanial activity of linalool-rich essential oil from Croton cajucara Benth. Antimicrob. Agents Chemother. 2003, 47, 1895-1901. 
6. Alviano, W.S.; Mendonça-Filho, R.R.; Alviano, D.S.; Bizzo, H.R.; Souto-Padrón, T.; Rodrigues, M.L.; Bolognese, A.M.; Alviano, C.S.; Souza, M.M.G. Antimicrobial activity of Croton cajucara Benth. linalool-rich essential oil on artificial biofilms and planktonic microorganisms. Oral Microbiol. Immunol. 2005, 20, 101-105.

7. Tullio, V.; Nostro, A.; Mandras, N.; Dugo, P.; Banche, G.; Cannatelli, M.A.; Cuffini, A.M.; Alonzo, V.; Carlone, N.A. Antifungal activity of essential oils against filamentous fungi determined by broth microdilution and vapour contact methods. J. Appl. Microbiol. 2006, 102, 1544-1550.

8. Sun, Q.N.; Najvar, L.K.; Bocanegra, R.; Loebenberg, D.; Graybill, J.R. In vivo activity of posaconazole against Mucor spp. in an immunosuppressed-mouse model. Antimicrob. Agents Chemother. 2002, 46, 2310-2312.

9. Dannaoui, E.; Meis, J.F.G.M.; Loebenberg, D.; Verweij, P.E. Activity of posaconazole in treatment of experimental disseminated zygomycosis. Antimicrob. Agents Chemother. 2003, 47, 3647-3650.

10. Azevedo, M.M.B.; Pereira, A.Q.; Chaves, F.C.M.; Bizzo, H.R.; Alviano, C.S.; Alviano, D.S. Antimicrobial activity of the essential oils from the leaves of two morphotypes of Croton cajucara Benth. J. Essent. Oil Res. 2012, 24, 351-357.

11. Stephan, J.; Mailaender, C.; Etienne, G.; Daffe, M.; Niederweis, M. Multidrug resistance of a porin deletion mutant of Mycobacterium smegmatis. Antimicrob. Agents Chemother. 2004, 48, 4163-4170.

12. Wiid, I.; Van Helden, E.H.; Hon, D.; Lombard, C.; Van Helden, P. Potentiation of isoniazid activity against Mycobacterium tuberculosis by melatonin. Antimicrob. Agents Chemother. 1999, 43, 975-977.

13. Maus, C.E.; Plikaytis, B.B.; Shinnick, T.M. Molecular analysis of cross-resistance to capreomycin, kanamycin, amikacin, and viomycin in Mycobacterium tuberculosis. Antimicrob. Agents Chemother. 2005, 49, 3192-3197.

14. Shandil, R.K.; Jayaram, R.; Kaur, P.; Gaonkar, S.; Suresh, B.L.; Mahesh, B.N.; Jayashree, R.; Nandi, V.; Bharath, S.; Balasubramanian, V. Moxifloxacin, ofloxacin, sparfloxacin, and ciprofloxacin against Mycobacterium tuberculosis: evaluation of in vitro and pharmacodynamic indices that best predict in vivo efficacy. Antimicrob. Agents Chemother. 2007, 51, 576-582.

15. Sartoratto, A.; Machado, A.L.M.; Delarmelina, C.; Figueira, G.M.; Duarte, C.T.; Rehder, V.L. Composition and antimicrobial activity of essential oils from aromatic plants used in Brazil. Braz. J. Microbiol. 2004, 35, 275-280.

16. van Den Dool, H.; Kratz, P.D.J.A. Generalization of the retention index system including linear temperature programmed gas-liquid partition chromatography. J. Chromatogr. 1963, 11, 463-471.

17. Adams, R.P. Identification of Essential Oil Components by Gas Chromatography/Mass Spectrometry, 4th ed.; Allured Business Media: Carol Stream, IL, USA, 2007.

18. Cruz, M.C.S.; Santos, P.O.; Barbosa, A.M., Jr.; Melo, D.L.F.M.; Alviano, C.S.; Antoniolli, A.R.; Alviano, D.S.; Trindade, R.C. Antifungal activity of Brazilian medicinal plants involved in popular treatment of mycoses. J. Ethnopharmacol. 2007, 111, 409-412.

19. Subha, T.S.; Gnanamani, A. Effect of active fraction of methanolic extract of Acorus calamus on sterol metabolism of Candida albicans. J. Appl. Biosci. 2008, 8, 243-250. 
20. Clinical and Laboratory Standards Institute (CLSI). Reference Method for Broth Dilution Antifungal Susceptibility Testing of Yeasts; Approved standard, M27-A2, CLSI: Wayne, PA, USA, 2002.

21. Clinical and Laboratory Standards Institute (CLSI). Reference Method for Broth Dilution Antifungal Susceptibility Testing of Filamentous Fungi; approved standard M38-A, CLSI: Wayne, PA, USA, 2002.

22. Clinical and Laboratory Standards Institute (CLSI). Susceptibility Testing of Mycobacteria, Nocardiae, and Other Aerobic Actinomycetes; approved standard M24-A, CLSI: Wayne, PA, USA, 2011.

23. Clinical and Laboratory Standards Institute (CLSI). Methods for Dilution Antimicrobial Susceptibility Tests for Bacteria That Grow Aerobically; approved standard M7-A6, CLSI: Wayne, PA, USA, 2006.

24. Khan, R.; Islam, B.; Akram, M; Shakil, S.; Ahmad, A.; Ali, S.M.; Siddiqui, M.; Khan, A.U. Antimicrobial activity of five herbal extracts against multi drug resistant (MDR) strains of bacteria and fungus of clinical origin. Molecules 2009, 14, 586-597.

25. Calvin, A.; Potterat, O.; Wolfender, J.L.; Hostettmann, K.; Dyatmyko, W. Use of On-flow LC/1H NMR for the study of an antioxidant fraction from Orophea enneandra and isolation of a polyacetylene, lignans, and a tocopherol derivative. J. Nat. Prod. 1998, 61, 1497-1501.

26. Mensor, L.L.; Menezes, F.S.; Leitão, G.G.; Reis, A.S.; Santos, T.C.; Coube, C.S.; Leitão, S.G. Screening of brazilian plant extracts for antioxidant activity by the use of DPPH free radical method. Phytother. Res. 2001, 15, 127-130.

Sample Availability: Not available.

(C) 2013 by the authors; licensee MDPI, Basel, Switzerland. This article is an open access article distributed under the terms and conditions of the Creative Commons Attribution license (http://creativecommons.org/licenses/by/3.0/). 